\title{
LA FAMILIA EN LA CONSTITUCION DE 1979
}

Héctor Cornejo Chávez

\begin{abstract}
Este estudio forma parte de la Exposición de Motivos de la Ponencia sobre el Libro de la Familia del nuevo Código Civil, presentado por el autor en su condición de miembro de la Comisión Revisora del Código de 1936.
\end{abstract}

\section{Las formas de celebración del matrimonio}

La Constitución de 1979 preceptúa en su Art. 5, párrafo segundo que las formas de celebración del matrimonio y las causas de su disolución serán reglamentadas por la ley.

Literalmente, y más allả de la intención del legislador contituyente, el texto del párrafo trascrito plantea la posibilidad de que el Código en preparación considere como formas de celebración del casamiento, no solamente la civil que introdujo con carácter facultativo o excepcional la Ley de 23 de diciembre de 1897 y que el Decreto-Ley 6889 convirtió en único y obligatorio a partir del 4 de octubre de 1930, sino también el matrimonio canónico que estuvo en vigencia durante los cuatro siglos anteriores y aún el servinakuy u otras formas matrimoniales de derecho aborigen.

\section{El matrimonio canónico}

El matrimonio ha sido históricamente regulado en diferentes formas, según que se haya visto en él una institución religiosa, civil o mixta.

En el Derecho Romano, el matrimonio sigue una progresiva tendencia que lo caracteriza como institución civil y que se pone de manifiesto en las diversas formas en que el marido adquiere la manus: la confarreatio, propia de los patricios, para cuya validez sólo es exigible la libre expresión del consentimiento y cuyas solemnidades religiosas no forman el matrimonio; la coemptio o venta solemne en que la secularización aparece claramente; y el usus, aplicación de la usucapio a la posesión de la mujer, en que es exclusivo el carácter profano. $\mathrm{La}$ índole civil de estas formas de matrimonio quiritario es aún más perceptible en el matrimonio sine manus, en el que la mujer sigue formando parte de su familia natural, sin confundir su patrimonio con el de su marido ni quedar sometida a la potestad de éste. La celebración de este matrimonio, que alcanzó consagración definitiva con Justiniano, no exige ninguna formalidad externa, pues es bastante el consensus matrimonialis, salvo cuando se trata de grandes dignatarios o personas ilustres que por disposición imperial deben otorgar dotalia instrumental. 
El matrimonio queda asi caracterizado como acto privado, no oficial y disoluble por divorcio o repudio.

En los primeros siglos de la era cristiana, el nuevo Derecho transige con el matrimonio civil de los romanos (y también de los bárbaros) para hacer más accesible el casamiento a los humildes y combatir el concubinato. Luego, hacia el siglo VI, comienza a fusionarse la legislación civil con la canónica; y tres siglos más tarde la Iglesia toma el matrimonio bajo su exclusiva regulación, hecho que se reafirma con las disposiciones adoptadas por los concilios de Letrán (s. XIII) y de Trento (s. XVI).

La concepción esencial del Derecho Canónico consiste en considerar el matrimonio como contrato y al mismo tiempo como sacramento, calidades ambas que se condicionan rec íprocamente: si no hay contrato válido, no hay sacramento; y si no hay sacramento, no hay contrato.

Durante varias centurias, el matrimonio y las cuestiones derivadas de él son consideradas universalmente como de exclusiva competencia de la Iglesia, y ésta los sujetó a una regulación exhaustiva que practicamente nada dejó de prever y en cuyo acierto debe hallrse la causa de su extraordinaria perduración.

La readquisición del Derecho matrimonial por la autoridad civil proviene de dos fuentes principales: el protestantismo, pues los reformadores rechazan la naturaleza sacramental del matrimonio; y el Derecho Natural, cuyos teóricos asumen en los siglos XVI y XVII la misma posición.

Más tarde, consumada la Revolución Francesa, el Còdigo Napoléon organizó el matrimonio como institución exclusivamente civil, influyendo con su ejemplo sobre casi toda la legislación del mundo.

Desde entonces y hasta antes de la II Guerra Mundial, las legislaciones adoptan una de tres posiciones principales: la puramente confesional; aquélla en que el Estado se arroga el derecho de regular el matrimonio, pero cuyas normas conservan una coloración confesional o admiten como supletorio el Derecho confesional en caso de insuficiencia de la regulación estatal; y la a-confesional, que prescinde de las normas religiosas aunque en mayor o menor extensión coincida con ella.

Contemporáneamente, el matrimonio civil -o forma civil de conclusión del matrimonio- se da subsidiario, facultativo u obligatorio, según los pa ises.

Es subsidiario cuando rige sólo para ciertos grupos de personas, para enlaces mixtos o para otros casos en que los contrayentes no pueden recibir la bendición eclesiática; tiene carácter facultativo cuando los interesados pueden casarse a su elección ante un eclesiásticó 'o ante un funcionario civil; es obligatorio cuando la ley desconoce todo valor al casamiento religioso e impone a los contrayentes sin excepción el matrimonio ante funcionarios del Estado. 
Austria hasta 1941; Inglaterra, Suecia, Italia y algunos Estados de la Unión Americana; Francia y otros paises, son respectivamente ejemplo de cada uno de esos criterios.

Entre los países latinoamericanos, los casos de Brasil, Colombia, Bolivia y Costa Rica resultan especialmente interesantes desde la perspectiva abierta por la nueva Constitución del Perú: todos ellos admiten o reconocen efectos civiles al matrimonio católico dentro de determinada medida y condiciones. Brasil es el de data más antigua, Colombia ha asumido esa posición como resultado de un Concordato con la Santa Sede, Bolivia y Costa Rica -que, como se ha dicho, son los países de más reciente regulación familiar $\mathrm{y}$, con Cuba, los únicos que legislan sobre el fenómeno familiar en códigos independientes- la han adoptado, a lo que parece, más bien en función de sus realidades sociales que por consideración de índole teórica.

En lo que concierné específicamente al Perú, el Código Civil de 1852 no estableció otro matrimonio con efectos legales que el celebrado conforme a las disposiciones del Concilio de Trento, es decir, el matrimonio canónico -tal como, por lo demás, ven í ocurriendo desde casi cuatro siglos antes, a raíz de la incorporación del Perú a la órbita de la cultura occidental-; si bien, para reclamar los derechos civiles anexos a él, era necesario inscribirlo en el Registro del Estado Civil (Arts. 441 y 443). Aquello se justificaba por el hecho de que la abrumadora mayoria de la población peruana profesa la religión católica.

Esa situación perduró hasta el 23 de diciembre de 1897, fecha en que se reconoció por ley dos formas de matrimonio: la canónica para los que profesaban la religión católica, y la civil para los que declaraban no haber pertenecido a dicha religión o haberse separado de ella; criterio éste que reafirmó la ley de 23 de noviembre de 1903 y que mantuvo la Comisión que preparó el actual Código Civil.

En 1920, el Congreso aprobó una ley que secularizaba el matrimonio; pero, observada por el Poder Ejecutivo en uso de sus atribuciones constitucionales, no pudo entrar en vigencia hasta el 4 de octubre de 1930, esto es, al retirarse el veto gubernativo por la Junta Militar de Gobierno de Sánchez Cerro (Decreto-Ley No. 6889).

A partir de entonces y hasta la promulgación del Código Civil de 1936, se llegó a prohibir a los sacerdotes católicos que celebrasen el matrimonio canónico mientras no comprobasen que los pretendientes habian contraido previamente matrimonio civil.

En la actualidad, derogada esa exigencia, la ley mantiene el precepto de que sólo el matrimonio civil produce efectos legales, sin que el caso del matrimonio in extremis o del matrimonio civil realizado ante funcionarios eleciástico hagan excepción, al menos expl 'citamente, a tal precepto. 
Ocurre, sin embargo, que la inmensa mayoría de la población peruana sigue considerándose casada cuando sale de la iglesia, y no de la municipalidad. Para ella, el matrimonio civil viene a ser poco más que un trámite previo al verdadero casamiento. Después de medio siglo de negación oficial de valor al matrimonio religioso, la realidad sigue resistiendo a esa imposición; y aunque se supone que en muchos casos se opta por celebrar ambos matrimonios, con la duplicación de trámites y gastos que ello importa, existen muchos otros en que se celebra sólo el religioso. Estos últimos casos, cuya verdadera magnitud no se conoce, crean el problema de que matrimonios que son verdaderamente tales en la intención y la convicción de los contrayentes, en su funcionamiento real y en el consenso colectivo, resultan ser concubinatos para la ley, con todos los inconvenientes y perjuicios que ello representa especialmente para la mujer y también para los hijos.

La iniciativa que, planteada al interior de la Comisión Principal de la Asamblea Constituyente, originó la norma contenida en el segundo párrafo del art. 5 de la nueva Carta, tiene por finalidad enmendar aquella anomalía. Con ella, al mismo tiempo que se hace concordar la ley con la realidad, se entiende respetar también la libertad de conciencia y de creencia, explícitamente consagradas como derechos fundamentales de la persona, ya que los contrayentes podrían casarse en cualquiera de ambas formas.

En tesis general, los obstáculos que es necesario superar en la implementación de la norma constitucional son principalmente tres: que los requisitos o condiciones necesarias para contraer matrimonio válido y lícito, y por tanto la teoría de los impedimentos, as i como la actitud frente a la disolución del vínculo, no son enteramente coincidentes en lo religioso y en lo civil; que los registros parroquiales no están bajo control del Estado; y que, con el mismo criterio, se debería reconocer valor legal a matrimonios contraidos conforme a otras creencias religiosas.

Conviene examinar separadamente cada uno de estos problemas:

Desde luego, las coincidencias entre las normas canónicas y las civiles acerca del matrimonio son muy grandes en cuanto a las formalidades (lo cual no puede llamar la atención, si se recuerda que, como lo hizo presente De Bernardi al iniciarse la obra legislativa de Napoléon, el Derecho Canónico perfeccionó a tal punto esta materia que las legislaciones civiles no han hecho sino copiarlo); difieren en cierta medida en cuanto a los impedimentos; y se contraponen abiertamente en lo que concierne a la posibilidad de disolver por divorcio el vínculo matrimonial y parcialmente en lo que atañe a la separación de cuerpos.

La diferencia, más bien pequeña como se ha señalado, en cuanto a las formalidades previas a la celebración del casamiento y a las de éste mismo, carecen de trascendencia, pues precisamente la Constitución admite la pluralidad de formas, aparte de que tanto las canónicas como las civiles persiguen las mismas finalidades y mantienen una gran semejanza. 
Más delicada e importante es la cuestión relacionada con la diferencia que, en cierta medida, se puede advertir en cuanto a las condiciones necesarias para casarse o teoría de los impedimentos.

Forzoso es, a este respecto, empezar por precisar cuáles son y en qué consisten tales diferencias.

Tanto el Código Civil como el Codex Iuris Canonici establecen los impedimentos dirimentes de impubertad, falta de consentimiento, vínculo conyugal pre-existente, consanguinidad en las líneas recta y colaterai, afinidad en ambas l íneas, rapto y crimen, y como impediente, el de adopción. No obstante, la coincidencia en la amplitud del impedimento sólo se da en los casos de consaguinidad y afinidad en línea recta, de vínculo conyugal anterior y de adopción. En general, también podria registrarse coincidencia en lo que concierne a la falta de consentimiento libre.

Hay un segundo grupo de impedimentos, que son los establecidos por el Código Civil y que no se reproducen en el Codex. Tales son los casos de la minoridad, la sanidad y las prohibiciones establecidas en los arts. 84 a 86 respecto del tutor y el curador y de las personas viudas, divorciadas o cuyo matrimonio anterior fue anulado.

Un tercer grupo se puede conformar con los impedimentos que sanciona e] Codex, pero que no vienen establecidos por el texto nacional, tales como los impedientes de voto simple de virginidad, de castidad perfecta, de no casarse, de recibir órdenes sagradas o de abrazar el estado religioso; el de mixta religión; el que prohibe el matrimonio del católico con quien ha dejado de serlo; y el que obsta el matrimonio con público pecador; y los dirimentes de impotencia, pública honestidad, parentesco espiritual y los que afectan al clérigo con órdenes sagradas, al religioso con ciertos votos y al bautizado respecto del no bautizado.

Es obvio que este último grupo carece de relevancia pa a el efecto de que ahora se trata, ya que siempre que la Iglesia sea más exigente que la ley nacional no se afecta en absoluto el orden público interno: en tales casos no se da la posibilidad de que logren contraer matrimonio religioso con efectos civiles quienes estuvieren impedidos de casarse por lo civil, que es lo que al Estado le interesa legítimamente En cuanto a los particulares afectados por tales impedimentos, legalmente podr casarse civilmente; el problema que con ello generan se sitúa estrictamente en la esfera intima de su conciencia moral o religiosa. Añádase un comentario pertinente a la impotencia; y es que, aunque el Código Civil no lo menciona como impedimento, permite la anulación posterior del matrimonio por esa causa, lo que aproxima más su posición a la canónica.

Tratándose del primer grupo de impedimentos, o sea, aquéllos en que ambas legislaciones coinciden, el único problema se refiere a la distinta amplitud en que cada una considera ciertos impedimentos, así como, eventualmente, en 1. posibilidad de que sean dispensados en una legislación y no en la otra (o 
concretamente en la legislación canónica y no en la civil, pues el supuesto contrario deja incólume el orden público nacional).

En este sentido, no existe problema derivado de la diferente amplitud del impedimento de consaguinidad en línea colateral, en el ue afinidad en la misma línea y en el de rapto (que incluye la retención violenta de la mujer, matiz que el Código Civil no incorpora al menos explícitamente); porque, en tndos ellos, la amplitud del impedimento es mayor en el Codex. Tampoco se da, pues, el riesgo de una violación del orden público nacional.

El problema queda circunscrito a dos casos de este grupo: el de impubertad y el de crimen, pues en ambos el texto civil es más exigente que el canónico. Este último considera púberes al varón de más de dieciséis años y a la mujer mayor de catorce y permite la eventual dispensa aún a edades menores; en tanto que el Código Civil fija la pubertad en dieciocho años, y sólo permite la dispensa cuando el varón ha cumplido diecisǐes años y la mujer catorce. Aunque la sanción de la infracción del impedimento en la ley civil es más bien benigna, lo que revela que no magnifica su importancia, podria limitarse la validez civil del matrimonio canónico a los casos en que los contrayentes tienen las edades que el Código Civil fija.

En cuanto al impedimento de crimen, los alcances que le atribuye el Codex -es decir, limitándolo al adulterio y al conyugicidio calificados- coincide con los de la mayoría de las leyes civiles del mundo; pero no con la nuestra, que comprende en el impedimento a todo aquél que haya sido condenado como part ícipe en la muerte de uno de los cónyuges o se halle simplemente procesado por tal causa (para contraer matimonio con la viuda o el viudo de su víctima). En zste caso, la solución tendría que ser, alternativamente, adecuar la ley peruana a la posición predominante al respecto en la legislación mundial; o negar validez al matrimonio canónico que se contraiga con infracción del impedimento.

Alguna diferencia en materia de dispensabilidad del impedimento carece de mportancia, pues el Codex no concede dispensa en casos que violen el orden júblico nacional.

Dentro de este mismo grupo conviene señalar una circunstancia peculiar que atañe al error en el consentimiento nupcial; hay coincidencia entre ambas legislaciones en cuanto al error en la persona del otro contrayente; pero en lo que concierne al error sobre algunas calidades de aq́uel, el Código Civil lo define como "ignorancia de algún defecto sustancial que haga la vida común insoportable" y precisa que "se reputan defectos sustanciales: la vida notoriamente deshonrosa; el haber sido condenado por delito a más de dos años de penitenciaría, relegación o prisión; la enfermedad incurable, trasmisible por contagio o herencia; y cualquier vicio que constituya peligro para la prole"; mientras que el Codex sólo lo considera como invalidante si es que redunda en error acerca de la persona misma. Si ha de interpretarse esta posición en el sentido de que tal error, al fin de cuentas, se reduce al error sobre la persona y 
no se extiende a la ignorancia de defectos como los puntualizados en la ley civil, la solución podría ser la antes sugerida para otros casos, a saber, que se dejaría abierta al cónyuge lesionado la posibilidad de plantear la anulación del casamiento.

Alguna diferencia existe también en el tratamiento de la vis compulsiva como vicio del consentimiento en ambos ordenamientos: en el nacional, debe tratarse de la amenaza de un mal grave e inminente para la vida, la salud, el honor, la libertad, una parte considerable de los bienes del amenazado, de sus ascendientes o descendientes; mientras que en el canónico el enunciado es más comprensivo, ya que sólo exige que una causa externa haya injustamente producido miedo grave al contrayente o lo haya forzado a casarse. A juicio del ponente, ésta es la fórmula que el Código debería asumir, con lo que, además, desaparecería el obstáculo de que ahora tratamos.

En lo que concierne al segundo grupo de impedimentos, esto es, a los que establece la ley civil y no la canónica consistir, alternativamente, en suprimirlo en el Código Civil o en exigir, para la inscripción del matrimonio canónico en el Registro del Estado Civil, la presentación del instrumento que acredite el consentimiento adicional de los padres, ascendientes o consejo de familia. Este último criterio se tendría que aplicar también en lo que concierne al certificado médico pre-nupcial o la declaración jurada supletoria. En lo que atañe, finalmente, a las prohibiciones contenidas en los Arts. 84 al 86 del Código Civil, los contrayentes del -... matrimonio canónico quedar ian sujetos a las mismas sanciones que para el casamiento civil establecen dichos artículos.

La dificultad consistente en que la ley canóniça no admite el divorcio y difiere de la ley civil en cuanto a las causales de separación de cuerpos, el obstáculo podría ser salvado recurriendo a una de las siguientes posibilidades: respetar la indisolubilidad del vínculo canónico libremente contraído por los interesados; referir al fuero civil la decisión al respecto, lo que equivale a circunscribir al acto del casamiento, y no al matrimonio como estado, la validez del celebrado con arreglo al Codex; o, a imitación de la estipulación incluida en algún concordato, el asunto se ventile y resuelva en la vía civil y conforme a las leyes civiles, pero que, en determinado momento, se dé noticias a la autoridad eclesiástica para que intente una reconciliación. En estas dos últimas posibilidades, los interesados asumirían responsabilidad por su decisión ante su propia conciencia: a semejanza del Código Civil vigente, éste se limitaría a recordar que sus disposiciones al respecto dejan incolumes los deberes que la religión impone, fórmula que, por lo demás, existía ya en el Código de 1852.

En cuanto a que los registros parroquiales no se encuentran bajo control del Estado -aparte de que ello no significa necesariamente que ofrezcan menos 
garantía que los municipales-, el obstáculo desaparece si se exige que, para surtir efectos civiles, el matrimonio canónico debe inscribirse en el Registro del Estado Civil, como, en términos un tanto equívocos, preceptuaba el Código de 1852 en sus Arts. 441-443.

Finalmente, el argumento de que, si se reconoce efectos civiles al matrimonio canónico, también deberían serles reconocidos a otras formas religiosas de casamiento, no parece suficientemente valedero, no sólo porque alguna de esas formas podría afectar al orden público interno, sino porque la razón principal que obliga a considerar el caso del matrimonio canónico reside en que la mayoría de los peruanos profesa la religión católica: se trata, en realidad, de una consideración sociológica antes que religiosa. Por lo demás, nada impediria a las personas que pertenezcan a otras confesiones contraer matrimonio civil para los efectos legales, sin perjuicio de que también lo contrajeran según sus propias creencias para efectos personales o de conciencia: para esos casos minoritarios, pues, la situación sería igual a la actual.

\section{EL SERVINAKUY}

Desde que la nueva Constitución, en lugar de hacer referencia específica al matrimonio canónico, prefirió remitir a la ley de la regulación de "las formas de celebración del matrimonio", y aunque ésta no haya sido la intención del legislador constituyente, ha quedado planteada la posibilidad de admitir el servinakuy como una de esas formas.

Abonaria, desde luego, esa posibilidad, aunque con menos énfasis que en el caso del matrimonio canónico, la razón sociológica que se acaba de recordar: el servinakuy, llámasele así o con otros nombres, es una suerte de unión matrimonial de Derecho consuetudinario que se practica desde hace siglos en extensos sectores de la población campesina del Perú.

Soslayado por mucho tiempo el problema por el legislador, y minimizado incluso a nivel de otros estudios sociales, tampoco ha sido frontalmente atendido en la nueva Constitución. Una fórmula concreta propuesta al interior de la Comisión Principal de la Asamblea Constituyente, no para conferir desde luego al servinakuy la calidad de forma matrimonial admisible, sino para empeñar al Estado en una inaplazable tarea de análisis del asunto, no prosperó.

Compete, pues, a la Comisión ocuparse del tema.

El término servinakuy no es quechua ni castellano, sino un híbrido surgido durante la Colonia. Se forma con la abreviación castellana servi, alusiva a servicio, y el afijo quechua nakuy, que tiene una connotación de mancomunidad, ayuda o participación. El vocablo resulta así suficientemente expresivo aunque eufemístico.

Señálese, por lo demás, que este nombre, aunque es el más conocido como 
referencia en el Perú occidental, no es unánimente utilizado por quienes practican esa forma de unión marital. La denominación varía según la región: se llama warmichakuy en el Cuzco, ujtasiña y sirvinakuy en parte de Puno, uywanakuy, servinaki o rimaykukuy en Ayacucho, Phaway tinkuska en Apurímac, Ch'ampatiqraqchay en Huancavelica, Muchada, civilsa o civilia en Junin, La pañaca servinakuy o sirvicia en Huánuco, Mushiapanaki, tinkunakuspa, watanakuy, taatsinakuy, mansiba o sirvinakuy en Ancash. No está, a nuestro juicio, suficientemente esclarecido si se trata sólo de diferentes nombres de un mismo fenómeno, o si aquellos esconden fenómenos diferentes en aspectos esenciales. Aparte de la comprobación de que el fenómeno se da en extensas zonas de la sierra central y meridional del pa is, no hay todavia datos bastantes para encontrar los elementos que uniformen eventualmente la figura. Esta insuficiencia explica, tal vez, por qué para algunos se trata de un matrimonio de prueba, para otros de un matrimonio por compra, en tanto que hay quienes prefieren denominarlo matrimonio natural, consuetudinario o sociológico.

Se trata, en todo caso, de un fenómeno socio-cultural de muy antigua raigambre, principal pero no exclusivamente en el Perú.

Von Tschudi, en su "Contribución a la Historia, Civilización y Lingüística del Antiguo Perú", afirma que la "cópula anticipada" existió en numerosos pueblos del Nuevo y Viejo Mundos.

Servinakuy, según George Rouma (Les Indiens Quitchuas et Aymaras des Hauts Plateaux de la Bolivie"), es el nombre dado al matrimonio a pruéba por los indios del altiplano boliviano. La prueba duraba un año y si de ella quedaba satisfecho el indio y si además esta unión tenía frutos se iba al casamiento, pero a veces el servinakuy duraba años.

Estas informaciones y opiniones guardan relación con antiguos testimonios de diversa fuente. "El mozo ha de venir a la casa del suegro cargado de leña y paja y chicha, y entonces el suegro le da su hija diciendo estas palabras: 'cata aqui a mi hija; si ella fuese mala, no me pongas la culpa, porque yo te dixe la verdad',," ("Relación de la Religión y Ritos del Perú hecha por los Primeros Religiosos Agustinos que alli pasaron para la Conversión de los Naturales", en la Colección de Libros y Documentos referentes a la Historia del Perú, por C. Romero).

El arraigo del servinakuy debió haber sido muy hondo desde que los españoles tropezaron con gran dificultad en su intento, no logrado sino en parte, de extirparlo: el Concilio Provincial de Lima, reunido en 1582, las Sinodales del Arzobispado de 1613 y las Ordenazas de Toledo prohibieron el "matrimonio a prueba'. a veces bajo penas severas.

No obstante, en 1621, según el testimonio de Arriaga ("Extirpación de la Idolatría en el Perú"), los mismos parientes de la mujer solían oponerse tenazmente al matrimonio si previamente no había hecho convivencia con el pretendiente; $y$ hasta el marido miraba con desprecio a la mujer a quien "nadie avia conocido ni querido antes que se casase". 
Es probable que, por la novedad del fenómeno a ojos de los conquistadores o por la deficiencia de sus investigaciones o por obra de los prejuicios, estas informaciones, no siempre congruentes, no correspondan por entero a la realidad. Se debe reconocer que esta situación se mantiene hasta hoy en buena parte.

En un meritorio trabajo de investigación basado en experiencias directas, Luis Ernesto Mercado Cárdenas ha recogido algunas aportaciones interesantes sobre la materia:

Así, la investigadora Zulma Zamalloa Gonzáles, refiriéndose a la cultura campesina del distrito de Sayllpata (Paucartambo, Cuzco), expresa que "el servinakuy viene después del rimanakuy; consistente en una etapa probatoria, en la que la mujer tiene que servir al hombre y éste trabajar para la mujer, mientras los padres hacen los preparativos del matrimonio, el cual es costoso y dura de tres días a una semana. Esto da lugar a que muchos no se casen por no poder soportar los gastos y se quedan con el servinakuy" ("Ciclo Vital en Sayllapata", Allpanchis, No. 4, Revista del Instituto de Pastoral Andina, 1972).

"Entre los indígenas del Cuzco se usa el matrimonio o rimayukuy, declaración de amor entre los padres. Hechas éstas, el novio se lleva a la novia a prueba y la prueba suele ser larga, pues a veces dura dos y tres años, al cabo de los cuales viene la separación que llaman ttacanacu, desconocerse, o continúa la pareja amancebada y el hombre siendo el "respeto" de la mujer" (Basadre, "Historia del Derecho Peruano", citando a Carlos Romero y a Alejandro Arancibia).

Dícese, de otro lado (Guillermina Calderón, "El Servinakuy en Debate", citando a Emilio Mendizábal) que "inicialmente fueron los sociólogos quienes se ocuparon de las uniones matrimoniales llevadas a cabo en la población andina.

Sea por deficiente información o por error metodológico, esos primeros estudios llevaron a la conclusión de que el matrimonio andino no existia. Estas uniones se llevaban a cabo sin obligaciones ni responsabilidades, dentro de una 'supuesta' institución a la que se le denominó 'matrimonio de prueba' o 'sirvinakuy' término este último tomado de los estereotipos mentales de la población mestiza”.

Los codificadores de 1936, por su parte, consideraron que el servinakuy "es un compromiso entre el pretendiente y el padre de la futura, quien contrae la obligación de recibir a su hija con prole y todo y la de devolver al pretendiente los obsequios recibidos o su equivalente en dinero o en trabajo si el enlace no llega formalizarse o a adquirir carácter duradero" (Actas de la Comisión Reformadoram fasc. 20 p. 122).

"El sirvinakuy o concubinato pre-matrimonial $-\mathrm{y}$ no 'matrimonio de prueba' como se le nombra vulgarmente-, muy arraigado en los departamentos de Juńin, Huánuco, Ancash y Huancavelica, consiste en que el hombre casadero 
toma una mujer, con conocimiento de sus padres y familiares, y convive con ella algunos meses o años" (Guamán Poma de Ayala, "El Derecho Inca").

Refiriéndose, por su parte, al warmịchajuy, Oscar Núñez del Prado ("El Hombre y la Familia: su matrimonio y organización político-social en Q'ero") sostiene que es "aquel en el cual, con un ritual sencillo y algunas frases estereotipadas, se constituye la unión de la pareja conyugal; una unión, que siendo reconocida por la sociedad, garantiza la permanencia de ella. La colaboración económica de las partes, su cohabitación residencial y sexual, y las consecuencias vinculadas a la herencia y la filiación legítima, es decir constituye sociológicamente un matrimonio real y con todos los atributos para establecer una unidad intermediaria entre el individuo y la sociedad, sobre una base conyugal..."

Alfonsina Barrionuevo ("Sirvinakuy: el matrimonio de prueba") ha dicho, por su parte, que "el sirvinakuy es una institución de Derecho natural que se basa, en primer término, en un profundo respeto a sus normas, respaldada por el control de los mayores (la sociedad) cuya palabra todavía es ley en las comunidades de la cordillera; y en segundo término, es un orden de propósitos bien establecidos... No se trata de tomar a 'prueba' una mujer, con el solo fin de convivir con ella y apreciar sus cualidades físicas y espirituales. En el sirvinakuy también el hombre tiene que someterse a un análisis, a una crítica justa de su conducta, de su capacidad tanto para crear y conducir una familia, cuanto para demostrar que puede mantenerla... Superado el año de prueba, con el esfuerzo y la buena voluntad de ambos, (es) ínfimo el número de parejas que se deshacen..."

En una posición crítica, Núñez del Prado (ob. cit.) dice textualmente: "mucho me temo que gran parte de las sociedades indígenas en que se considera el sirvinakuy como matrimonio de prueba, no (se trate) sino de un error debido a la observación algo superficial o también al hecho harto frecuente de que los observadores tomen como referencia única los patrones de su propia cultura, tratando de identificarlos por su forma, antes que por su función. De aquí que se tome en cuentra sólo la práctica ceremonial con desmedro de la institución fundamental, auténtica... De nuestra parte, estamos en condiciones de afirmar que, por to menos en Q'ero, no existe el sirvinakuy de que hablan los sociólogos".

De otra parte, se suele describir el fenómeno como un proceso de convivencia entre varón y mujer y se manifiesta en dos fases: una pre-concubinaria y otra concubinaria. En la primera no hay vida en común y puede o no haber relaciones sexuales esporádicas. Comprende dos etapas: el aqllanakuy y el munaykukuy. El primero significa seleccionarse mutuamente. La elección es independiente de la voluntad de los padres o de terceros. En el segundo se desarrolla una vida sentimental amorosa y esotérica: los enamorados son adictos a la adivinación de su futuro, acuden al watucuq o adivino...' $\mathrm{El}$ destino (o kausay pacha) del hombre y su familia depende del destino de la 
mujer que haya escogido... Una vez realizada la unión definitiva, aún en el supuesto de haberse constatado la incompatibilidad del kausay pacha de la pareja no es ya posible separarse... y deben las personas aceptar su nuevo estado hasta el fin"... (Núñez del Prado, ob. cit.)' La segunda fase del servinakuy -se agregacorresponde al concubinato, previa la celebración de ciertos ritos para hacer pública la convivencia, estrechar los lazos entre ambas familias y crear las bases económicas de la unión.. Este proceso presenta tres etapas: el rimaykukuy (diálogo o conversación en que la joven, luego del rapto, vuelve al hogar paterno acompañada del marido y de los padres y familiares de éste (lo que ocurre también si no ha habido rapto previo). La actitud del varón es entonces muy cortés, poética, suplicatoria. Casi siempre se produce esta visita por la noche); el kintuy o masticación ceremonial de la coca que consolida la unión y en el cual los padres se aprestan a hacer los anticipos de herencia; y el tiakuy o tinkukakuspa, que es ya la convivencia (fusión).

Frente a este cúmulo de apreciaciones, divergentes a veces aun en materia de hechos, Mercado Cárdenas deduce que "muchos han definido el servinakuy a partir de sus rituales y costumbres exóticas; asi, por ejemplo, como matrimonio de compra, por los obsequios que se otorgan los 'contrayentes'; como un servicio, por los trabajos realizados sea por el varón, por la mujer o por ambos durante las relaciones concubinarias; y como matrimonio de prueba en razón del tiempo de la convivencia para 'probar' la compatibilidad de caracteres o bien las aptitudes domésticas y laborales de cada cual".

En su mencionado trabajo, recoge sin embargo, diversos testimonios de los cuales fluiría la semejanza entre el servinakuy y el matrimonio tal como lo concibe el Código: la comunidad toda, por ejemplo, repudia al hombre o a la mujer que hallándose en servinakuy mantiene relaciones sexuales permanentes o esporádicas con tercera persona (suerte de adulterio al que se llama pantanakuy, que significa 'camino equivocado'; la comunidad sólo admite que el q'ari (varón adulto) conviva en servinakuy con la p'asña (mujer de 16 a 20 años), que pueden estimarse púberes; las personas que sufren de alteraciones mentales no participan por lo general en el servinakuy (si bien ello debe atribuirse, no a la insuficiencia del consentimiento, sino a la ineptitud para el trabajo, razón por la cual tampoco participan en el servinakuy los tullidos, ciegos, sordomudos, mancos o cojos); los padres y familiares de la pareja contribuyen, mediante anticipos de herencia o regalos, a la ofrmación de un patrimonio; cada uno de los miembros de la nueva familia -el padre, la madre, los hijos-, tiene su propia función, etc.

Son circunstancias como las reseñadas las que han inducido a varios estudiosos a sostener que el servinakuy - con este nombre o con otroconstituye en verdad un matrimonio 'sociológico' o 'de derecho natural o consuetudinario', suficientemente definido, profundamente arraigado, considerablemente difundido y merecerdor, por ello, de no seguir siendo ignorado por el ordenamiento oficial del país. Son ellas también, sin duda, las que explican por qué, por ejemplo, el Decreto-Ley No. 17716 sobre reforma agraria ha acogido la figura. 
El panorama asume aún complejidad mayor -o por el contrario, entreabre una posibilidad de solución- si es que, parece, el servinakuyy llega. a ser en algunos lugares una etapa previa al matrimonio católico, y no al civil. En la comunidad de Sayllapata, dice Zulma Zevallos (ob.cit.) "muy pocos son casados civilmente. El poco conocimiento que el campesino tiene de las leyes de su país no le permite entender cuán importante son los efectos del matrimonio civil, especialmente para el futuro de los hijos".

Sobre la base de su propia experiencia como maestros en escuelas situadas en comunidades indígenas del Cuzco, Mercado Cárdenas señala la vigorosa presencia del cristianismo entre los indigenas: casi no hay uno que no haya sido bautizado, la celebración de festividades religiosas es costumbre muy arraigada y durante el servinakuy se realiza el casarakuy, que es el matrimonio católico.

En definitiva, parece no haber consenso en cuanto a determinar si el servinakuy es hoy una experiencia previa al matrimonio católico, o si, una vez cumplida, se hace permanente sin formalización canónica ni civil, o si es, desde su inicio, un "matrimonio sociológico o de derecho consuetudinario" con vocación de permanencia indefinida.

Se conoce, pues, la existencia del fenómeno, el área geo-demótica de su práctica, varias de las denominaciones que recibe, algunas de las características que lo tipifican según los lugares, y la presencia de factores ancestrales, educativos, geográficos, económicos y jurídicos que contribuyan a su persistencia; mas no existe todavía, que sepamos, un esfuerzo sistemático para allegar información más completa y detallada, para someterla a una apreciación crítica, para integrar orgánicamente los elementos cuya gravitación sea seriamente comprobada, para configurar, en suma, un cuadro al mismo tiempo completo, coherente, profundo y extenso, sobre cuya base sea posible diseñar una politica legislativa y fijar un tratamiento jurídico-legal adecuado (además, por cierto, de otras políticas no jurídico-legales cuya importancia es igual o aún mayor).

En tanto no exista esa base, difícilmente podría el Código Civil asimilar el servinakuy al matrimonio o incluirlo entre las formas de celebrarlo. Todo lo más, y de momento, acaso convendría facilitar la formalización civil de aquellas uniones mediante la ampliación, en favor de organismos formados por la autoridad educativa, el jefe del consejo de la comunidad campesina y un miembro de ésta electo por sus integrantes, de la atribución de delegar la facultad de intervenir en la celebración del matrimonio a que se refiere el art. 115 del actual Código Civil, aunque extendiéndola a todas las etapas del tramite y no sólo a la ceremonia final; y la correlativa modificación del art. 29 referente al registro del estado civil, aparte de la labor que siga realizando la iglesia católica en la difusión del matrimonio canónico que ya tendría efectos civiles. 
Consagrada constitucionalmente la igualdad del varón y la mujer ante la ley (art. 2 inc. 3), esta proclamación de berá tener importantes consecuencias en la regulación civil de la familia.

En el Código vigente, se atribuye al marido la dirección del hogar, las decisiones referentes a su economía, la de fijar y mudar el domicilio común, la representación legal de la sociedad conyugal frente a terceros, la administración del patrimonio común, el ejercicio prevalente de la patria potestad sobre los hijos matrimoniales y la carga principal del sostenimiento de la mujer y los hijos. La mujer, además, necesita el consentimiento de su marido para desempeñar un trabajo fuera del hogar. Debe añadir al suyo, el apellido de su marido como una expresión exterior de su condición subordinada. Sólo en situaciónes excepcionales, la mujer asume la dirección y representación de la sociedad; a ella sola le está reservado el derecho de pedir la separación de bienes durante el matrimonio, con la excepción del mutuo acuerdo; y a ella sola, en fin, le están dedicadas las figuras de la dote y los bienes reservados.

En armonía con la Constitución, el nuevo Código tendrá que incorporar normas que sancionen el diálogo entre los cónyuges en lugar de la imposición o la supremacía de uno sỏbre el otro; y, en consecuencia, la dirección conjunta del hogar, incluso en lo que concierne a la economia doméstica y al domicilio común; la representación indistinta del marido y la mujer para las necesidades de la vida ordinaria y la conjunta para los demás actos; el ejercicio por ambos de la patria potestad sobre los hijos de matrimonio y de concubinato; el derecho igual de ambos para trabajar lucrativamente para el sostenimiento del hogar; la modificación del régimen patrimonial por uno o más sistemas que den a la mujer las mismas atribuciones que al marido; y acaso la desaparición de las figuras de la dote -que, además, debe desaparecer por causa del desuso y su anacronismo- y de los bienes reservados. En rigor, también debiera modificarse la actual norma acerca del apellido de la mujer casada, a fin de que en cada caso los cónyuges decidan que apellido llevar, o que cađa cual mantenga el suyo propio. No obstante, el ponente estima, en lo que respecta a este último punto, que los inconvenientes derivados de quebrar una tradición centenaria no tendrían en este caso particular la contrapartida de ventajas que justifiquen el cambio.

\section{Paternidad responsable, anticoncepcional, aborto, inseminación artifícial}

El art. 6o., párrafo 1, de la nueva Carta declara que "el Estado ampara la paternidad responsable". La Comisión deberá decidir si este enunciado, novedoso en nuestros esquemas legales y al mismo tiempo ambiguo, determinará modificaciones en el ordenamiento civil.

El concepto de paternidad responsable no es todavía bastante nítido: Hay quienes lo vinculan al problema de la explosión demográfica, característico de los países emergentes. El crecimiento apresurado de la población, a un ritmo que 
en los casos más agudos sobrepasa el 4o/o del año, genera, como es natural, problemas importantes de alimentación, vivienda, salud, educación y empleo, entre otros. Estos problemas llegan a alcanzar contornos catastróficos y, tanto por ello cuanto por la magnitud planetaria del problema, constituye una de las más ansiosas preocupaciones del mundo contemporáneo. En el caso del Perú, la tasa de crecimiento demográfico es de un $2.90 / 0$, menor a la de muchos países subdesarrollados pero bastante mayor que la de los países industrializados.

Para quienes tienen presente este problema, la paternidad responsable lleva implícito un significado de control de la natalidad, principalmente a base de anticoncpetivos artificiales y del aborto legalizado. Este planteamiento suscita, en concepto del ponente, varias reflexiones:

Conviene recordar, en primer lugar, que la preocupación frente al incremento de la población no es de ahora. Hace dos siglos, Malthus la expresó también en términos dramáticos: el crecimiento de la población en progresión geométrica, frente al de los alimentos en progresión aritmética, lo indujo a vaticinar, con base aparentemente cientifica, un futuro desastre mundial. Es bien sabido que el vaticinio no se cumplió, porque el desarrollo de la ciencia y de la técnica, no sólo permitió aumentar la producción de aliemntos en escala gigantesca, sino que llegó a producir excedentes. El actual progreso de la ciencia y la tecnología no es en modo alguno menos sustancial que el de principios del siglo pasado.

En segundo lugar, el Perú es un país semi-despoblado, tanto en razón de su área geográfica -equivalente a la de Alemania, Francia e Inglaterra juntas-, cuanto por la magnitud de sus recursos naturales y potenciales.

Sería pertinente añadir otras dos consideraciones importantes: a nivel global, no parece que pueda hablarse de escasez de alimentos y otros recursos económico-financieros, pues mientras en una parte del mundo el problema es de escasez, en la otra es más bien de desperdicio; y, en otra perspectiva más directamente vinculada al tema que nos ocupa, paternidad responsable en los países desarrollados se da, presumible pero no cuantificablemente, con tanta frecuencia como patemidad responsable en los países emergentes.

En definitiva, la paternidad es responsable cuando no entienden agotarse con el simple acto de procrear, sino asumir, además el deber de contribuir a asegurar a los hijos condiciones adecuadas de realización. La patemidad responsable necesita, así, por una parte, disponibilidad de bienes -porque los haya y porque se esté capacitado para adquirirlos-y, de otro lado, sentido moral de la propia responsabilidad. La paternidad es más irresponsable cuando se tiene bienes y se carece del sentido del deber -y la crisis moral no es privativa del mundo pobre - que cuando, teniéndose el sentido del deber, no se tiene acceso a bienes suficientes para alimentar y formar a los hijos. Irresponsable es la patemidad que se desentiende del problema de la subsistencia y educación de los hijos. Irresponsable es la limitación de la natalidad cuando se quiere dedicar los 
bienes de que se dispone al mantenimiento de un nivel de desperdicio, lujo o vicio. Es posible que lo primero se dé con mucha frecuencia en los países subdesarrollados. Es seguro que lo segundo se registra en los desarrollados.

La raiz del problema parece inscribirse, pues, en la mala distribución y el mal uso de la riqueza y de la renta, además de hallarse en la producción y la productividad insuficientes; y ello puede darse, y ciertamente se da, tanto a nivel mundial (como lo revela el diálogo tenso entre el Norte y el Sur o la desproporción entre lo que se gasta en ayuda y lo que se destina a armamentos), como a nivel nacional (cuando se gasta en obras faraónicas lo que debiera invertirse en nutrición, vivienda, salud o educación) y a nivel de las familias (como cuando se limita la natalidad para no afectar niveles desahogados de consumo superfluo).

Es obvio que tamaño problema rebasa los ámbitos de lo jurídico-legal y ciertamente los del ordenamiento civil de la familia.

Más si, en fin de cuentas, existe un problema de crecimiento desorbitado de la población, de ello no podría derivarse como solución obligada la del empleo de métodos artificiales de anticoncepción ni por cierto la del aborto, desde que existen otros métodos de limitación racional de la natalidad.

En todo caso, si la suscinta reseña del grave problema que se acaba de hacer fuese correcta, parece obvio que no corresponde al Código Civil preceptuar, permitir o prohibir el empleo de medios anticonceptivos artificiales o naturales. El tema incumbe a otras áreas de la acción pública y privada, así como al fuero inviolable de la conciencia de cada quien.

Considera, pues, el ponente que no es del caso legislar en torno del significado, alcances y consecuencias del principio constitucional que ha proclamado el amparo estatal de la patemidad responsable, en lo que concierte al empleo de aquellos métodos de control de la natalidad.

Regulación legal sí es pertinente acerca del aborto: en el campo institucional, en cuanto a determinar los alcances del derecho a la vida del ser humano; en el penal, en lo que concieme a la calificación del aborto como acto ilícito o lícito; y en el civil, en lo tocante al comienzo de la personalidad y en cuanto al pretenso derecho de los padres a decidir la continuación o truncamiento del proceso de gestación del hijo.

Sobre el particular, el art. 2 de la nueva Constitución proclama en su párrafo 1 que toda persona tiene derecho a la vida y que, al que está por nacer, se le considera nacido para todo lo que le favorezca. Aunque con algún eufenismo, esta norma proscribe el aborto. $Y$ lo proscribe con entero fundamento, a juicio del ponente, pues la persona humana comienza en el momento mismo de la concepción, es decir, de la fecundación del óvulo por el espermatozoide: no sólo considerando que entre ese ser y el que luego habrá de 
nacer, desarrollarse y morir no hay diversidad esencial ni metamorfosis, sino identidad; sino también teniendo en cuenta que, como lo atestigua la ciencia, todas las calidades que el hombre desarrollará a lo largo de su existencia están ya presentes en el concebido, dentro de un esquema de programación genética que establece una intima e indisoluble vinculación de identidad entre el concebido y el nacido.

Incumbe también, al menos teóricamente, a la normación legal de la familia la cuestión de la inseminación artificial de la mujer casada. Obvios y arduos problemas, sobre todo referentes al deber de fidelidad, al adulterio como causal de separación de cuerpos o de divorcio, y a la paternidad, pueden ser generados en este campo. Aparte de apuntar una cierta contraposición que se da entre la preocupación frente a la explosión demográfica y cualquier empeño de facilitar la inseminación artificial, el ponente considera que, importante como es el tema a nivel teórico, no ha llegado el momento de legislar en nuestro país al respecto: no existe en la realidad problema que demande una solución.

$\mathrm{Si}$, no obstante, se considerase oportuno hacerlo, piensa el ponente que habria que distinguir varios supuestos, tales como el de la fecundación artificial de la mujer casada con semen del marido (ordinariamente con el consentimiento de éste, pero también si no lo diera); el de la fecundación con semen de tercero, con consentimiento del donante y del marido; el de la fecundación con semen de tercero, sin consentimiento o contra la voluntad del marido; y, en fin, el de la fecundación y gestación en laboratorio en cualquiera de los supuestos anteriores.

Descartado de momento este último supuesto, pues ni siquiera en vía experimental se ha registrado algún caso, que se sepa, el ponente expresa su posición contraria a la legalización de todos los demás, por razones morales; y que si hubiera de situarse el problema en sus alcances exclusivamente jurídicos, sólo el primero de los casos propuestos podria exonerarse de la tacha de deslealtad de la mujer (que sería pertinente en el tercer supuesto) o de falseamiento de los fines del matrimonio y de la naturaleza de la filiación matrimonial (que podría hacerse en las hipótesis segunda y tercera). Dicha segunda hipótesis tendría que ser considerada como un ilícito (civil en los cónyuges y penal en el facultativo). La tercera tendría que constituir, además, causal de separación de cuerpos y de impugnación de la patemidad.

\section{El patrimonio familiar}

El parágrafo final del art. 5o. de la nueva Constitución remite a la ley el establecimiento del "patrimonio familiar inembargable, inalienable, trasmisible por herencia".

La norma se resiente de cierta oscuridad debido a que la misma denominación utilizada es equívoca o ambivalente ya que en el Código Civil actual se consagra hasta tres figuras vinculadas con los bienes de familia. 
En cuanto a lo primero, la expresión patrimonio familiar podría parecer referida a los bienes que sustentan la vida de la familia - esto es, lo que el código vigente llama bienes comunes-y a las obligaciones que con tal fin se contraigan. En cuanto a lo segundo, existen, en efecto, las fundaciones de familia, la indivisión de la herencia y el hogar de familia, dentro del ordenamiento actual.

No obstante, la denominación de patrimonio familiar para referirse a un concepto diferente del patrimonio común de la sociedad conyugal se ha generalizado en la doctrina y la legislación de numerosos países, y desde que la Constitución la emplea también no parece aconsejable, ni demasiado importante, denominarlo de otro modo, acaso más exacto e inequívoco, en el nuevo Código.

Por lo demás, el patrimonio familiar de que ahora tratamos podría incidir sobre lo que actualmente se llama hogar de familia o tal vez involucrar las tres figuras antes mencionadas, esto es, ser el nuevo nombre de los "bienes de familia".

De nuestra parte, nos inclinamos en el sentido de que el Código debe impiementar la norma constitucional como referida al hogar de familia, suprimir las disposiciones de aquél en cuanto a las fundaciones familiares -que bien pueden referirse por lo establecido en el título de las fundaciones en general-y suprimir también las normas referentes a la indivisión de la herencia, pues de ella se trata también en el Libro de las Sucesiones.

Aunque parece reconocer antecedentes de muy antigua data, el hogar de familia es relativamente reciente en la legislación nacional, ya que no existió en el Código 1852.

Inmediatamente recogida por el codificador peruano de las leyes suiza y brasilera, se piensa generalmente que su origen contemporáneo se encuentra en el homestead norteamericano, especialmente en su modalidad del homestead exemption. Extendiendo la investigación a épocas muy anteriores, hay quienes consideran que en la conocida prescripción contenida en el Cap. 24 vers. 6 del Deuteronomio podría ubicarse el antecedente más antiguo de la figura y que también es posible hallar idea semejante en el herkis del Derecho griego, del cual lo habrian tomado los romanos, o en el heredium establecido por éstos.

Por semejante manera, en lo que concretamente hace a la legislación nacional, se ha creído hallar antiguos y reiterados antecedentes en el Código de 1852 , arts. 1579,1699 y 2238 ; en los arts. 1153 a 1155 del antiguo Código de Enjuiciamientos Civiles; de modo muy expresivo en la ley de 14 de noviembre de 1900 y en la complementaria de 16 de octubre de 1911; en el art. 617 del Código de Procedimientos Civiles de 1912; y en la ley 6619, entre otras menos próximas al concepto.

A. nivel de la doctrina, es notable el caso del jurista don Miguel Antorio de la Lama, quien, a principios del siglo presente, preconizaba la dación por el Congreso de una ley que realmente contenía todos los elementos del futuro hogar de familia. 
Como se reseñará más adelante, al promulgarse el Código Civil de 1936. que recogió la iniciativa, se suscitaron en torno a ella encontradas opiniones.

En apoyo del hogar de familia, se suele invocar razones de orden social, económico y moral. Entre las primeras se suele mencionar que contrarresta el éxodo del campo a la ciudad y de los nacionales hacia el exterior, frena la tendencia a la atomización de la propiedad territorial sobre todo agrícola, consolida el grupo familiar, lo mantiene unido, y neutraliza el fenómeno de desarticulación y dispersión de la familia, factores propios del estilo contemporáneo de vida que vienen ocasionando grave daño al organismo social.

Desde el punto de vista económico, se afirma que el hogar de familia favorece la mediana propiedad agrícola, artesanal o fabril y evita la disolución de empresas individuales que de otro modo desaparecerán al morir su propietario.

A partir, en fin, de un enfoque moral, el hogar de familia reviviria lazos de afecto y solidaridad entre sus miembros y asi contribuiría a afirmar los vínculos filiales y fraternos de la familia, prolongaría la vigencia real del hogar a través del tiempo y aseguraría el amparo de los más débiles por los más fuertes en el seno del mismo núcleo doméstico.

Siendo exactos algunos de estos conceptos, otros parecerían pecar de un cierto anacronismo y carecer de la eficacia que sus autores les asignan para neutralizar determinados fenómenos de la vida moderna, como el del éxodo campesino sobre las urbes, que son, por cierto, mucho más complejos y de más ardua solución.

Por el contrario, hay quienes consideran inconveniente la figura, porque inmovilizaria la propiedad de ciertos bienes retornando en alguna medida a la superada figura de las vinculaciones; porque constituiría un duplicado inútil del derecho de habitación; y sobre todo porque, lejos de ser una ventaja para las familias de ajustada condición económica, podría estorbar su desenvolvimiento.

El primero de estos argumentos, que es técnicamente exacto, no nos parece sin embargo suficiente para cerrar paso a la posibilidad de constituir un hogar de familia, ya que la conveniencia o inconveniencia de vincular ciertos bienes por determinados motivos no constituye un dogma jurídico cuya observancia obligue a atar o constreñir las exigencias de la realidad.

Corresponde, en cambio, examinar la objeción consistente en que el hogar de familia podría constituir un duplicado del derecho de habitación, pues esta duda podría erigirse en un cuestionamiento de la sustantividad y la naturaleza jurídica de la figura, y aún podría hacer innecesaria su creación.

A partir del texto del Código vigente, la semejanza aparece obvia a poco que se diga, como dicen los arts. 951 y 952, que "el derecho de usar o de servirse de un bien no consumible se rige por las disposiciones (del usufructo) en cuanto le sean aplicables" y que "cuando el derecho de uso recae sobre una casa o parte de ella para servir de morada, se estima constituído el derecho de habitación". 
No obstante, parecen existir algunas diferencias entre el hogar de familia y el derecho de habitación. Así, en éste el propietario sigue o puede seguir usando o disfrutando del bien, en unión de otras personas de su familia, mientras que en el usufructo el nudo propietario cede esas facultades en favor del usufructuario. Así, igualmente, la finalidad específica del hogar de familia, las formas de su constitución, la especificidad de los beneficiarios, la adquisición o extinción del derecho en virtud de la prescripción, y otras menos relevantes.

La cuestión carece, sin embargo, de importancia por dos principales motivos: que la Constitución ordena la implementación del hogar de familia o patrimonio familiar en el título de los derechos de la familia, por lo cual resultaria impropio que el nuevo Código dejara de hacerlo; y porque, en la hipótesis de que efectivamente el hogar de familia no fuese otra cosa que un derecho de habitación peculiar, de ello no podría inferirse que no cabe legislar sobre él, específicamente o que no quepa insertar su normación en el Libro de la Familia y no en el de los Derechos Reales.

Tal vez la principal observación a la figura no sea del orden jurídico-legal, sino práctico: que, lejos de constituir una ventaja para las familias de ajustada situación económica, pueda llegar a estorbar su desenvolvimiento, ya que. precisamente por ser ingravable, inenajenable, inembargable e inarrendable el inmueble sobre el cual se constituye el hogar de familia, su propietario no puede obtener con la garantía de éstos el acesso al crédito que hoy es indispensable en la actividad económica y aún en la vida ordinaria de cualquier particular, ni obtener, por vía de locación o venta, el dinero que puede necesitar con urgencia. Las familias pobres difícilmente tienen la posibilidad de constituir un hogar de familia porque carecen de un inmueble de su propiedad que afectar; o, aun teniéndolo, pueden necesitar ofrecerlo en garantía, arrendar total o parcialmente $\mathrm{y}$ aun venderlo como único recurso ante ciertas contingencias de la vida, de modo que, en caso de inmovilizarlo mediante la constitución de un hogar de familia, la figura estaria, no favoreciéndolas, sino perjudicándolas en momentos singularmente difíciles. En otra hipótesis, muy generalizada al presente, las familias suelen lograr la adquisición de un inmueble, quizá el único, financiando su costo mediante préstamos de tipo hipotecario, lo que significa que no puede afectarlo como hogar sino cuando haya terminado de pagar su precio. Por su parte, las familias pudientes no necesitarán recurrir a la garantía del hogar de familia para asegurar el porvenir de sus miembros, pues su propia condición económica lo hace innecesario o porque otras formas de seguro les resultarán más accesibles, dinámicas y atractivas.

Es verdad que la nueva Constitución parece liberalizar un tanto la rigidez que tiene el hogar en el Código vigente, desde que, si bien quiere que sea inalienable e inembargable, no pide que se prohiba su eventual arrendamiento total o parcial, lo que puede ser necesario por razones especiales $\mathrm{y} / \mathrm{o}$ temporalmente; pero como se mantiene las otras restricciones $-\mathrm{y}$ éstas han de ser mantenidas en efecto, pues sin ellas no quedaria nada del hogar de familia- 
subsistirá la posibilidad de que la figura tenga en adelante tan escasa aplicación como hasta hoy.

Contradiciendo, en efecto, tanto el pronóstico optimista del Dr. Cockbum, que auguró al hogar de familia una copiosa aplicación y considerables beneficios, como el que pesimistamente anunció Angel Gustavo Cornejo, quien estimaba que la figura seria perjudicial, la realidad desmintió ambas predicciones por el simple camino de un virtual desuso: en 1938, por ejemplo, no sólo por su volumen demográfico, sino por la predominancia de la población urbana en la que suele suponerse un mayor conocimiento de la ley- sólo se registraron 39 casos de constitución de hogar de familia; en 1947, el número bajó a 27; y en 1965 había descendido a 12, cifras éstas que, no obstante ser incompletas, parecen revelar una tendencia hacia el desuso total.

Es verdad que con motivo de la dación de la Ley No. 13500 se advirtió un aumento inusitado del fenómeno, más ello no modifica sustancialmente aquella apreciación desde que el llamado hogar de familia en dicha ley difiere considerablemente de la figura tal como está sancionada en el Código Civil, ya que se estableció por via de autoridad, se contradijo la norma contenida en el art. 471 de dicho cuerpo de leyes y se prescindió de lo preceptuado en los arts. 467 inc. 10., 462 y 468 .

Con estos antecedentes, pudiera considerarse excesivo que la figura, no sólo se mantenga, sino que haya sido elevada a la jerarquía constitucional. En realidad, sin embargo, ni la figura es, necesariamente y por su misma esencia, inviable y obsoleta, ni faltan de ella numerosos ejemplos en la legislación civil comparada.

Respecto de esto último, conviene recordar que con diferentes nombres y algunas peculiaridades, el patrimonio familiar inalienable, inembargable y a veces hereditario existe en el Brasil, Colombia, Uruguay, México, Costa Rica, Argentina, Ecuador y Bolivia, entre otros paises americanos, asi como en Francia, Italia, Alemania y Suiza, entre los europeos.

Acerca de lo primero, ha de señalarse que, aunque las razones de la inoperancia práctica de la figura en el Perí tiene que ver fundamentalmente con la estructura socio-conómica imperante, también se vinculan en alguna medida con las deficiencias de su ordenamiento legal, tal como aparece contenido en el Código Civil de 1936. Esto último, pues, puede corregirse en el nuevo texto, a partir de la norma constitucional.

Este contiene, prima faciae, dos innowaciones interesantes, a saber: no prohibe que el hogar àe iamilia pueda ser objeto de locación-conducción; y añade la trasmisibilidad hereditaria a las características del hogar de familia.

Desde que nadie está impedido de hacer lo que la ley no prohibe, parecería, pues, que en el nuevo Código Civil podría permitirse el arrendamiento del hogar 
de familia, más esto sólo deberia, en nuestro concepto, ocurrir en dos casos: el de exigirlo así, a juicio del juez, una emergencia sobreviente y de carácter temporal, o el de necesitar la familia para su mismo sostenimiento reducirse a una parte del inmueble para alquilar la otra. Extender a otros supuestos aquella posibilidad desnaturalizaría la figura y podría llegar a privarla por entero de su propia razón de ser.

En lo concerniente a la trasmisibilidad hereditaria del hogar, el Código actual establece que aquél dura mientras viva el constituyente y sólo por excepción permite que se prolongue por disposición del propietario o hasta que llegue a la mayoría el más joven de los hijos. Acierta en la innovación la Carta de 1979, en opinión del ponente, al modificar esta situación, pues el hogar se establece no tanto en beneficio del constituyente, sino de aquellos miembros de su familia que de él dependen y principalmente de su cónyuge y de sus hijos menores, Por tanto, la regla general debería ser que el hogar subsista mientras dichos familiares vivan, sin que el aplazamiento de la participación deba originar como ahora ocurre, un derecho indemnizatorio de los herederos mayores de edad.

La ley deberá, por otra parte, perfeccionar el régimen actual del hogar de familia precisando sobre qué bienes, si sólo los propios de uno de los cónyuges o también sobre los comunes, es posible constituirlo; si sólo el jefe de la familia pueda establecerlo, como lo preceptúa el Código vigente y entonces quień tiene tal carácter a tono con la Constitución, o si debiera permitirse, como creemos, que la constituya también tercera persona; si las deudas por cuyo pago se puede embargar los frutos del hogar son las que actualmente prescribe la ley o si, como pensamos, debiera eliminarse las referentes al seguro de incendio.

Otras modificaciones del régimen actual, que tampoco derivan de la norma constitucional, serán explicadas al tratar específicamente de la figura. Ellas inciden en la administración del hogar, los casos de extinción y, tal vez, en el trámite para su constitución y eventual oposición.

\section{El concubinato}

Una de las innovaciones más importantes de la nueva Constitución, porque se refiere a un problema de graves contornos en el Perú, incide en el concubinato.

Aunque no existen datos suficientes al respecto, algunos de los que recogió el Censo Nacional de 1972 resultan ilustrativos. Sobre un total de 2'642,992 mujeres mayores de 12 años que, en esa oportunidad, declararon hacer o haber hecho vida marital, resultaron:

Casadas

Viudas
$1 ' 609,164$
316,770
60.88 \%

$11.98 \mathrm{o} / \mathrm{o}$ 
Separadas

Divorciadas

Convivientes
638,907
$2.46 \%$

$0.48 \%$

$75.80 \%$

$24.17 \%$

Es de presumir que el número real de hogares concubinarios es mayor del que aparece en el cuadro que antecede, ya que, por consideraciones de prestigio social o de pudor social, si asi quiere llamaŕsele, o por convicción, personas que son convivientes para la ley se declaran o se sienten realmente casadas,

Pero aún ateniéndonos a las cifras del Censo, es obvio que el número de hogares constituídos sobre una base no matrimonial es alto. Los datos trascritos no permiten sub-clasificar todos esos casos; pero presumiblemente entre ellos hay que distinguir al menos tres situaciones distintas:

a) Los casos de verdadero concubinato, semejante al que se da también en otros paises, esto es, aquellos casos en que un varón y una mujer, sin ser casados, hacen vida de tales;

b) Los casos de matrimonio católico exclusivamente;

c) Los del llamado servinakuy o designado con otras denominaciones usuales entre los campesinos indigeneas de la sierra central y meridional del país.

Ahora bien, las dos últimas situaciones no son en realidad casos de convivencia concubinaria. El canónico es un verdadero matrimonio. El servinakuy ha sido calificado de "matrimonio sociológico" y ambos son fenómenos cuya existencia, evidente y masiva, se ha empeñado en ignorar la ley peruana a veces por consideraciones extra-juridicas. Convivencia marital concubinaria sólo la hay en la primera de dichas situaciones.

No obstante, la nueva Constitución no ha acogido el planteamiento -propuesto durante los debates por el autor de esta nota- de iniciar una política legislativa tendiente a dar una solución racional y realista, al mismo tiempo que justa, al problema del sirvinakuy; y ha remitido a la ley, en términos equívocos, la posibilidad de reconocer efectos civiles al matrimonio religioso, como ya se ha expresado.

En contraste, sí se ha ocupado del concubinato propiamente dicho, a cuyo respecto preceptúa que "la unión. estable de un varón y una mujer, libres de impedimento matrimonial, que forman un hogar de hecho por el tiempo y en las condiciones que señala la ley, da lugar a una sociedad de bienes que se sujeta al régimen de la sociedad de gananciales en cuanto es aplicable".

Quedan, así, comprendidos los casos en que un varón y una mujer, que no son casados, pero que podrían serlo, hacen vida marital; pero excluídos los quie no son casados ni podrian serlo. Este criterio nos parece correcto.

En realidad, la nueva Constitución, al incluir la norma que se acaba de 
trascribir, no ha hecho sino culminar una línea de tendencia que se inició hace mucho tiempo.

En el campo del Derecho Civil, ya la Comisión Reformadora del Código de 1852, cuyo trabajo culminó con la promulgación del actual Código Civil de 1936, abordó el problema de las uniones de hecho, si bien el aspecto que más le preocupó fue el del eventual enriquecimiento del concubino a costa de su compañera en el caso de que aquél abandonara a ésta (aspecto, sin duda, importante, pero no único de las uniones de hecho).

En esa oportunidad, se discutió acerca de cuál podría ser una solución adecuada del mencionado problema; y se recordó las distintas soluciones planteadas a nivel de la doctrina jurídica: la de considerar la unión concubinaria como una sociedad de hecho, a los efectos de que, una vez disuelta también de hecho, los ex-socios se distribuyeran el activo líquido; o la de considerar este caso como el de una locación de servicios, a fin de que la mujer pudiese exigir el pago de remuneraciones no canceladas por el trabajo realizado durante el concubinato. Se hizo notar entonces, sin embargo, que ambas soluciones resultaban forzadas. Mal podía afirmarse la existencia de una sociedad mercantil o aún civil, desde que no existia la affectio societatis, esencial al concepto de sociedad; y menos aún ver en la relación concubinaria una figura de locación de servicios.

La Comisión Reformadora terminó por aceptar el criterio expuesto por uno de sus miembros, el Sr. Olaechea, en el sentido de que el problema de la posible expoliación de la mujer abandonada por su concubino podría ser resuelto, sin necesidad de legislar sobre el concubinato, mediante la aplicación de la norma contenida en el art. 1149, según el cual "aquél que se enriquece indebidamente a expensas de otro, está obligado a la restitución".

A base de este criterio, la jurisprudencia de los tribunales ha reconocido en diversas oportunidades el derecho de la concubina a exigir que se le reconozca la propiedad sobre una parte del patrimonio acumulado en común, aunque sujeto a la probanza respectiva, que frecuentemente es muy difícil en lo que concieme al grado de participación de cada interesado en la adquisición de bienes durante la convivencia.

En otros campos ajenos al Derecho Civil, existen también antecedentes importantes, algunos de los cuales afrontaron el problema de las uniones de hecho de un modo mucho más directo.

Así, las leyes No. 8439 de 20 de agosto de 1936 (es decir, contemporánea del nuevo Código Civil) y No. 8569 de 27 de agosto de 1937, aunque sir nombrar expresamente el caso de la concubina, resultan comprendiéndola con referencia a la compensación por tiempo de servicios en caso de fallecimiento del trabajador; y más recientemente se hizo explícito el reconocimiento del fenómeno concubinario, primero en el D.L. No. 17716, de 24 de junio de 1969 , 
sobre reforma agraria, al tratar de la caducidad del contrato de compra-venta por fallecimiento del campesino sin haber cancelado el precio; y después en el D.L. No. 20598 de 30 de abril de 1974 , sobre empresas de propiedad social, al regular la trasnferencia de certificados de retiro al fallecimiento del trabajador.

Como es notorio, en casi todos estos casos el problema que ha concitado la atención del legislador ha sido el referente a la propiedad de bienes; pero no ha considerado otros aspectos importantes, como el de los alimentos, la herencia o la indemnización del daño moral.

La nueva Constitución no ha hecho, pues, otra cosa que culminar una tendencia que ya venía desarrollándose por algunas décadas; y tampoco ha abordado los problemas alimentario, hereditario o indemnizatorio a que se acaba de hacer referencia.

Toda normación sobre esta materia puede ser objeto de controversia. Los antecedentes y la legislación comparada traen sobre el concubinato ejemplos de variado tratamiento:

En Roma, el concubinato, aunque poco honroso para quienes lo practicaban y especialmente para la mujer (que perdía, si era ingenua y honrada, la consideración social y el título de mater familias),, no era ilícito, ni era practicado arbitrariamente, sino que estaba suje to a determinadas reglas. No llegaba a ser, sin embargo, un matrimonio.

Entre los germanos también existió el concubinato; sobre todo para las uniones entre libres y siervos; el cual fue después sustituido por el llamado matrimonio morganático.

En la legislación medjeval de España se acogió, con más o menos amplitud y en vista de viejas costurabres, el matrimonio de bendiciones, el matrimonio de yuras o juramentado y la barraganía.

En el campo de la legislación comparada contemporánea, dos casos, entre los de más antigua data, merecen especial mención: el de la ley soviética, que al principio reconoció el "matrimonio de hecho", hasta que el 8 de julio de 1944 volvió al antiguo sistema que negaba valor legal a esa forma de unión; y el Código de Mëxico para el Distrito Federal, de 1932, que reconoce, en ciertas circunstancias, un derecho alimentario y otro hereditario a la concubina, aunque sin convertir al concubinato en matrimonio.

Entre las legislaciones americanas la evolución parecería seguir un curso semejante al de México: originalmente mostraron renuencia para aceptar el concubinato como fenómeno jurígeno de tipo matrimonial y al presente parecerían orientarse en sentido inverso, como en el caso de Bolivia, que acepta la "unión conyugal libre", y en cierta medida el peruano, a través de la nueva Constitución.

En cambio, en Rumania, China Popular y Cuba podrían ser ejemplos de la 
actual tendencia del mundo socialista a limitar al matrimonio la protección de la ley, rectificando así la orientación primigenia de la Unión Soviética.

Con relación a este problema, es pertinente mencionar una preocupación generalizada: si en la medida que se legalice el concubinato no se está desestimulando el matrimonio. En realidad, ninguna legislación está en contra del matrimonio; pero el tipo de garantias que se ofrezca a la unión concubinaria y los derechos que de él se deriven pueden tener aquel efecto indeseable. Esta es, presumiblemente, la razón de que un sector de la doctrina se incline en el sentido de que la ley debe ocuparse del concubinato, pero con miras a su gradual extinción. Esta podría ser la posición del Código de Familia de Cuba. No es, infortunadamente, la de la nueva Constitución peruana.

Conviene precisar, en todo caso, la limitada extensión de la reforma constitucional: ella no alcanza sino al concubinato strictu sensu; y sólo lo alcanza en algunos aspectos patrimoniales, mas no en los personales.

El nuevo Código debe precisar el tiempo y las condiciones del concubinato para que funcione como una sociedad de bienes. En cuanto a lo primero, todo plazo es ciertamente arbitrario. En la Comisión Principal de la Constituyente se llegó a sugerir uno de veinte años. La idea no fue secundada. En el Derecho Comparado se halla ejemplos en que la duración mínima de la unión para surtir ciertos efectos se fija en cinco años (o haber tenido hijos, alternativa importante ajena a todo plazo). Tal es el caso del Código de México para el Distrito y Territorios Federales. El Código de Familia de Bolivia no señala plazo alguno para que la "unión conyugal libre" sea tenida como un matrimonio legal en cuanto a los efectos que produce.

El ponente considera que un plazo de cinco años puede ser aceptable:

En cuanto a los demás requisitos concurrentes a los que la nueva Carta se refiere bajo el nombre de "condiciones", el concepto no aparece claro. Desde luego, la denominación no tiene el alcance técnico de la condición como modalidad del acto jurídico; parece más bien empleado en su sentido vulgar, como sinónimo de elementos o requisitos. Más tampoco aparece claro a qué otros requisitos podría el legislador sujetar el reconocimiento de una unión concubinaria como una sociedad de bienes, aparte de los de ausencia de impedimento nupcial y singularidad que la propia norma constitucional exige. Acaso se podría puntualizar al respecto la nota de voluntariedad en la decisión de los interesados y precisar la cohabitación, la fidelidad y la asistencia como caracteres del hogar de hecho.

El Código deberá, asismismo, remitir la calificación de los bienes de los concubinos como propios o comunes, el ejercicio de las facultades de administración y disposición de aquéllos y éstos, asi como las cargas que pesan sobre unos y otros, a lo que se establece para la sociedad de gananciales en el Título referente al régimen patrimonial del matrimonio. 
Otras dos materias deberán ser concretamente reguladas con normas propias, es decir, distintas de las que el Código trae para el matrimonio: la de la pnueba del concubinato, que, a nuestro juicio, deberá referirse a la posesión constante del estado a partir de fecha aproximada, cuestión para cuya probanza podrán usarse, en cuanto sean aplicables, los medios que señala el texto procesal civil, siempre que exista un principio de prueba escrita; y la del fenecimiento de la sociedad de bienes, que sólo podrá producirse por muerte, ausencia, mutuo acuerdo o decisión unilateral, caso este último en que, en determinadas circunstancias, el concubino abandonado o inocente podrá ejercer un derecho indemnizatorio.

\section{Hijos matrimoniales y extramatrimoniales}

El parágrafo final del art. 6 de la nueva Constitución proclama que "todos los hijos tienen iguales derechos"; y agrega que "está prohibida toda mención sobre el estado civil de los padres y la naturaleza de la filiación de los hijos en los registros civiles y en cualquier documento de identidad".

La innovación significa también la culminación de una línea de tendencia universal al respecto:

Las antiguas legislaciones consagraron, no solamente una diferencia muy grande entre ambas filiaciones, sino que deprimieron a la ilegítima; en lo cual no hacian sino reflejar un estado social de ánimo muy arraigado.

Los más radicales distinguieron, no sólo a los hijos legítimos de los ilegítimos o bordes, sino que sub-clasificaron a estos últimos en naturales y espurios; volvieron a sub-dividir a los últimos en fornezinos, sacrilegos y mánceres; y zubclasificaron una vez más a los primeros en adulterinos o notos e incestuosos (incluyendo a los nefarios).

La tendencia universal contemporánea se dirige a reducir la distancia que anteriormente existía entre los hijos legítimos e ilegítimos. En algunos casos, se ha suprimido la diferencia (Constitución Cubana, Constitución de la República Española, Código de Familia de la Unión Soviética, de Rumania, de Cuba, de Bolivia y otros).

Entre nosotros, el Código Civil de 1852, aunque sin semejante drasticidad, mantuvo la diferencia entre legítimo e ilegítimo y la sub-clasificación de éstos c n naturales, y no-naturales (con especial y casi exclusiva referencia a los adulterinos).

El actual Código Civil, aunque ha suprimido formalmente esa sub-clasificación, la mantiene materialmente en varios casos, como el del art. 315 , que restringe la posibilidad de legitimar por sub-siguiente matrimonio tratándose de hijos adulterinos e incestuosos.

La Constitución de 1933 guarda silencio al respecto. 
Importante como es la innovación $-\mathrm{y}$ discutible también,-, no tiene, sin embargo, efectos demasiado espectaculares o novedosos:

En efecto, eran ya escasas las diferencias legales entre ambas clases de hijos. En el campo del Derecho Civil se circunscribían básicamente al apellido, la legitimación, la patria potestad y la herencia. En cuanto al primero, el art. 361 del Código establece que el hijo ilegítimo solamente lleva un apellido: el del padre o la madre que lo reconoció, o si ambos lo hubieran reconocido, el del padre. Es preciso admitir, sin embargo, que ésta diferencia resultó en la práctica poco significativa, ya que, por la vía del desuso, los hijos ilegítimos reconocidos por ambos padres han llevado en la práctica ambos apellidos. Ya se mencionó, por otro lado, la diferencia establecida por el art. 315 entre los hijos adulterinos e incestuosos para el efecto de la legitimación por sub-siguiente matrimonio.

En cuanto a la patria potestad, el hijo ilegítimo, conforme a lo dispuesto en el art. 395, está bajo la de uno solo de sus padres, mientras que sobre el legítimo la patria potestad se ejerce por ambos.

En lo que concieme a la herencia, el art. 762 reduce la cuota del hijo ilegítimo a la mitad de la que corresponde al legítimo, cuando concurren unos y otros; el art. 765 limita la herencia del cónyuge a la cuarta parte de la herencia, en el caso de haber hijos legítimos (lo que no rige en el caso de haber sólo ilegítimos); y el art. 712 hace perder la facultad de libre disposición al testador que mejora a sus descendientes dejando hijos ilegítimos reconocidos; norma que, aparentemente, no es de aplicación cuando hay sólo hijos legítimos. La innovación constitucional borra las mencionadas diferencias.

Discutiblemente, podria tener también efecto en el parentesco legal derivado de la adopción. Se podría argüir, acerca del art. 33, que al limitar el parentesco proveniente de la adopción al adoptante y al adoptado y sus descendientes legítimos, está recortando un derecho a los legítimos, lo cual conträriaría la norma constitucional.

Otras diferencias, de haberlas, serian poco significativas.

La norma bajo comentario no contiene, en realidad, innovación en cuanto a la prohibición de mencionar la filiación de los hijos en los registros civiles y en cualquier documento de identidad, porque, con parecidos alcances, ya existía esa norma en la legislación nacional. La novedad consistiría en haberla elevado a jerarquía constitucional.

Es importante destacar que la declaración de que "todos los hijos tienen Ios mismos derechos" no significa que hayan de dezaparecer del Código Civil todas las disposiciones contenidas en los Títulos sobre Filiación Legitima, Adopción, Filiación Ilegítima ni las pertinentes del Título de Patria Potestad, desde que los derechos de los hijos se ejercen frente a sus padres, lo que implica la necesidad de saberse quiénes son éstos. 
Ahora bien, la vinculación de una persona con sus padres aparece muy clara, aún desde antes del nacimiento de esa persona, cuando es habida en relaciones matrimoniales.

Este fenómeno se debe a dos razones principales: en primer lugar, el matrimonio ata a los cónyuges con el deber de fidelidad, que importa la renuncia que cada cual hizo, libre y voluntariamente, a la posibilidad de tener trato sexual con tercero, e impone a ambos el débito sexual. Por el principio de que, mientras no se demuestre lo contrario, se presume que las personas cumplen sus deberes y se comportan honorablemente, se supone que el embarazo de una mujer casada es obra de su marido.

Esta vinculación lógica y automática, que otorga certidumbre y fijeza al status del hijo legítimo, no se da en el hijo ilegitimo. Este podrá, por lo general, señalar ciertamente a su madre, pero será mucho menos fácil que ubique ciertamente a su padre.

En segundo lugar, el nacimiento de un hijo legítimo constituye, ordinariamente, un acontecimiento que, no sólo no se oculta, sino que más bien se exhibe y hasta se publica; que se espera por los padres y sus relacionados como un evento venturoso; y que, por lo mismo, señala a los progenitores incluso desde antes de nacer el hijo.

Lo contrario suele ocurrir tratándose de la filiación ilegítima, salvo la que tiene su origen en un concubinato ostensible.

Mientras tratándose del hijo legítimo, el emplazamiento en su status surge del hecho del matrimonio de sus padres y del juego de presunciones bastante robustas en cuanto a los términos minimo y máximo de fetación, cuando se trata del hijo ilegítimo no existen tales factores. De hecho y de derecho, no hay más que dos maneras de que el hijo ilegitimo lograse emplazamiento: el reconocimiento voluntario y la declaración judicial de la patemidad o de la maternidad.

En consecuencia, todo lo referente a la presunción pater is est quem nuptiae demonstrant tratándose del hijo legítimo, asi como al reconocimiento voluntario y la investigación judicial tratándose de los ilegítimos, habrá de quedar básicamente en pie. Quedará también vigente el status del llamado "hijo alimentista"; e igualmente el del hijo ilegítimo no reconocido ni declarado, ni alimentista.

En cambio, podrá desaparecer la figura de la legitimación por devenir innecesaria o inútil, ya que convertir en matrimonial al hijo extramatrimonial no tendrá relevancia alguna en cuanto a sus efectos. Sólo una consideración de índole subjetiva podría explicar su mantenimiento. En general, los códigos que han suprimido la diferencia entre los hijos han eliminado también la legitimación. El de Rumanía, por ejemplo, se refiere a ello en el prefacio del Prof. Ionesco.

De otro lado, los hijos deberán dejar de ser denominados legítimos e 
ilegítimos, pues estas calificaciones parecen aludir al hecho de estar dentro de la ley o fuera de ella, lo que contradiria ei espiritu de la Constitución. De esto, empero, no deberá inferirse que recibirán la misma denominación, pues ello confundiría la normación referente al reconocimiento voluntario, la declaración judicial de paternidad o maternidad, el asentamiento de partidas de nacimiento y otras cuestiones semejantes. Los códigos que suprimen la diferencia entre los hijos o los igualan en sus derechos optan por llamarlos hijos de padres casados y no casados, como hace el de Bolivia; o habidos dentro del matrimonio o fuera de él, como el de Costa Rica.

El ponente cree que estas denominaciones son aceptables. 